\title{
LA UNIVERSIDAD Y EL ESTADO ${ }^{1}$
}

por Jaime Lavados Montes

Cada año, con motivo de la conmemoración del aniversario de la Univ sidad de Chile, el Rector de la Corporación hace un recuento de los m importantes logros alcanzados en el período, así como de las principa políticas y orientaciones estratégicas que se han diseñado, y de problemas y dificultades que han debido enfrentarse.

Quiero aprovechar la celebración de este nuevo aniversario para ar lizar, como un hecho de creciente y problemática importancia, el ver dero asedio a que se ha venido sometiendo a la Universidad en e último tiempo, así como a examinar las causas y consecuencias de e situación.

Hablo de asedio porque es difícil encontrar otra palabra que descr mejor el enorme flujo de informaciones hechas sobre la base de supu tos de débiles fundamentos, desde puntos de vista sesgados, y de análi inconsistentes, que se han venido publicando y difundiendo acerca de Universidad de Chile, de su gestión, su eficacia, su eficiencia, y hasta su validez y su razón de ser.

Aunque, como he señalado, los fundamentos de tal flujo informat sean débiles, éste no puede dejar de tencr consecuencias negativas pa la Universidad, puesto que tiende a distorsionar la percepción quc tiene de ella en la comunidad nacional, generando imágenes que lleg a ser casi caricaturescas.

Dichos efectos negativos se manifiestan también en el ámbito inter por las dificultades de comunicación que se producen dentro de $\iota$ institución que tiene la complejidad de ésta, que reúne una gran dive dad de unidades académicas y de especialidades, además de los obv matices y diferencias generados por las distintas concepciones y sens: lidades que conviven en una institución plural como la nuestra. Des luego es difícil mantener una información fluida acerca de nuestra sit ción general, que llegue oportunamente a todas estas unidades, tallere 


\section{IÑIGO DÍAZ CUEVAS}

Médico Veterinario de la Universidad de Chile, con estudios de posgrado en el área de la producción animal, profesor titular (1985), autor de más de 50 publicaciones científicas, autor y coautor de 7 libros en las áreas de la Producción y Salud Animal y Educación Superior. Además es autor de más de 100 ponencias en congresos y symposia e investigador responsable en alrededor de 20 proyectos de investigación.

Fue Presidente del Centro de Alumnos (1968-1969) y Secretario Comisión de Reforma de su Facultad (1968), Secretario General Asociación de Académicos de la Universidad de Chile (1984-1990), Presidente Colegio Médico Veterinario de Chile (1985 - 1990), Decano Facultad de Ciencias Veterinarias y Pecuarias. Universidad de Chile (1990-1994 y 1994-1998), Senador Universitario Universidad de Chile (2002-2006) y Vicerrector de Asuntos Académicos de la Universidad de Chile (2006-2010). 


\section{UNIVERSIDAD VIGILADA, UNIVERSIDAD ASEDIADA Iñigo Díaz Cuevas}

Históricamente la palabra del Rector de la Universidad de Chile ha sido considerada como una señal que orienta no solo el sistema universitario, sino que adquiere la fuerza de la opinión de una de las más altas autoridades de la República, sobre todo si se expresa en el contexto de un aniversario de nuestra Corporación. Es el caso del presente documento, entregado a la comunidad universitaria y al país en noviembre del año 1994, para el aniversario no 152 de la Universidad de Chile.

Con la perspectiva que dan estos 15 años de devenir institucional del sistema de educación superior chileno, se puede señalar que esas palabras del rector Lavados configuran un pensamiento adelantado. Los aspectos que se abordan pueden ser hoy día casi rutinarios, pero al mismo tiempo, de plena actualidad. Así también los énfasis que acentúa el discurso son, en gran medida, rescatables también hoy.

Se introduce el discurso haciendo ver "como un hecho de creciente y problemática importancia" lo que el Rector define como "el verdadero asedio a que se ha venido sometiendo a la Universidad en este último tiempo", entregando también el aporte rectoral, un claro análisis de posibles causas y consecuencias de lo anterior. Para los que vivimos de cerca la intervención militar de nuestras universidades, estas consideraciones planteadas a cuatro años del término de la dictadura, toman sentido profundo y de brutal realidad, haciéndonos recordar aquel célebre artículo de Jorge Millas, publicado en la década del 80, titulado la "Universidad Vigilada".

Universidad asediada, universidad vigilada, es sin lugar a dudas, el tema actual de nuestra Universidad de Chile y a lo mejor de la educación universitaria estatal, producto del discurso caricaturesco, mantenido durante tantos años, acerca de las eventuales deficiencias administrativas, de su labor académica, del mal uso de los recursos, por mencionar algunos de los argumentos escuchados majaderamente, los que han constituido "un sistemático acoso" sobre nuestra universidad.

Estas adelantadas palabras tienen hoy, afortunadamente y después de tantos años, una propuesta concreta en los planteamientos del Nuevo Trato con el Estado, encabezados nuevamente por la actual rectoría de la Casa de Bello, tendiente a transparentar esta indispensable relación sobre la base de obligaciones y deberes, pero también de los derechos que merece la educación superior pública.

Se establecen también aspectos institucionales, como la necesidad de que las instituciones universitarias complejas, como la nuestra, dispongan de mecanismos de información interna y externa, que permitan la participación más activa de las unidades académicas y de sus profesores y de la comunidad, al mismo tiempo que eviten las distorsiones en la percepción de la comunidad nacional sobre ellas. 
En aquella época, el rector Lavados destaca la tremenda heterogeneidad de los sistemas de educación superior, la falta de indicadores para medir calidad, excelencia, eficiencia y pertinencia, la necesidad de alivianar las trabas administrativas a que son sometidas las instituciones, la precariedad de los aportes estatales y la necesidad de dar cuenta pública y de ser responsables del rol que debemos seguir teniendo frente a la sociedad.

Los planteamientos institucionales del rector Lavados, expresados a pocos años de recuperadas la dignidad académica y la democracia son, sin lugar a dudas, palabras adelantadas. 


\section{LA UNIVERSIDAD Y EL ESTADO ${ }^{1}$ por Jaime Lavados Montes}

Cada año, con motivo de la conmemoración del aniversario de la Universidad de Chile, el Rector de la Corporación hace un recuento de los más importantes logros alcanzados en el período, así como de las principales políticas y orientaciones estratégicas que se han diseñado, y de los problemas y dificultades que han debido enfrentarse.

Quiero aprovechar la celebración de este nuevo aniversario para analizar, como un hecho de creciente y problemática importancia, el verdadero asedio a que se ha venido sometiendo a la Universidad en este último tiempo, así como a examinar las causas y consecuencias de esta situación.

Hablo de asedio porque es difícil encontrar otra palabra que describa mejor el enorme flujo de informaciones hechas sobre la base de supuestos de débiles fundamentos, desde puntos de vista sesgados, y de análisis inconsistentes, que se han venido publicando y difundiendo acerca de la Universidad de Chile; de su gestión, su eficacia, su eficiencia, y hasta de su validez y su razón de ser.

Aunque, como he señalado, los fundamentos de tal flujo informativo sean débiles, éste no puede dejar de tener consecuencias negativas para la Universidad, puesto que tiende a distorsionar la percepción que se tiene de ella en la comunidad nacional, generando imágenes que llegan a ser casi caricaturescas.

Dichos efectos negativos se manifiestan también en el ámbito interno por las dificultades de comunicación que se producen dentro de una institución que tiene la complejidad de ésta, que reúne una gran diversidad de unidades académicas y de especialidades, además de los obvios matices y diferencias generados por las distintas concepciones y sensibilidades que conviven en una institución plural como la nuestra. Desde luego es difícil mantener una información fluida acerca de nuestra situación general, que llegue oportunamente a todas estas unidades, talleres y laboratorios, que, centrados en sus propias tareas y lenguajes disciplinarios, suelen desinteresarse por los aspectos más globales de nuestra vida institucional. Estas circunstancias aumentan nuestra vulnerabilidad, especialmente frente a la información sesgada que viene desde fuera o alguna proporcionada desde dentro, por grupos o personas más interesadas en lograr sus propios fines que en la suerte de la institución. Nótese, al pasar, que nuestra complejidad y nuestro pluralismo son, al mismo tiempo, causas de nuestra riqueza y de nuestras dificultades, cuestión que no existe para otras instituciones de Educación Superior, sea porque son menos complejas o porque son más homogenéas que nosotros desde un punto de vista doctrinario, social o político.

No es la primera vez que la Universidad se ha visto expuesta a un sistemático acoso. Todos recordarán que durante el Régimen Militar se hizo lo posible por reducirla, y usé el término "reducir" no en el sentido de la racionalización administrativa, sino en el de someter, de disciplinar, de despojar del ejercicio de ese pensamiento crítico, que nunca es visto con simpatía por los regímenes autoritarios. El problema ahora es ¿cómo y por qué se genera hoy, en una sociedad abierta, pluralista y democrática esta situación de asedio?

Pienso que hay varias razones que podrían explicar, si no el asedio mismo, sí la falta de comprensión que muestran distintos actores relevantes de la política y de la sociedad, respecto de la Universidad de Chile. Creo, además, que precisamente es esta carencia de entendimiento acerca de nuestros trabajos y actividades la que genera serias dificultades de interpretación y análisis, y

1 Discurso del Rector de la Universidad de Chile con motivo del $152^{\circ}$ aniversario de la Corporación. 
hace posible la acción de quienes están interesados, por cualquier razón, en proyectar las visiones más negativas acerca de nuestra realidad.

Para explicar estos hechos deseo destacar, en primer término, la tremenda heterogeneidad de los sistemas de Educación Superior en Chile, a lo que se suma la falta de indicadores específicos, objetivos y neutrales para medir la calidad y la eficiencia de las instituciones de este nivel educativo. Esta insuficiencia analítica abre la oportunidad para que la mayor parte de la información que habitualmente circula sobre Educación Superior tenga un carácter eminentemente publicitario y, por lo tanto, ella se diseña, prepara y produce no con el fin de generar un conocimiento confiable, sino con el de obtener mejores posiciones en la competencia que se ha generado entre las instituciones de este nivel, sea para captar a los estudiantes con los mejores puntajes en el proceso de selección, para atraer recursos a través de la venta de servicios académicos y de investigación, o para mejorar perfiles e imágenes corporativas.

A lo anterior se agrega la falta de políticas universitarias de Estado y de carácter nacional tan largamente reclamadas por esta Universidad y cuya carencia produce toda suerte de incoherencias y desajustes entre propósitos propiamente académicos y regulaciones jurídico-administrativas, lo que a su vez incrementa la sensación de ineficiencia y desorden. Últimamente, además, se suman, y con creciente fuerza, factores ideológicos o doctrinarios que se manifiestan en una diversidad tan grande de demandas y denuncias, que sería imposible satisfacer a unas sin lesionar otras, lo que se explica, de paso, por la falta de consenso existente en el país en relación al rol y a las características que debieran tener las Universidades del Estado.

Creo necesario profundizar en el análisis de estos factores.

\section{HETEROGENEIDAD DE LA EDUCACIÓN SUPERIOR EN CHILE}

Para nadie es un misterio que cuando hablamos de un sistema de Educación Superior en Chile sólo estamos usando un constructo linguístico, que no tiene mucho asidero en la realidad.

Si dentro del término incluimos no sólo a los diversos tipos de Universidades, sino además a los Institutos Profesionales y a los Centros de Formación Técnica, es fácil comprobar que ellos tienen como único denominador común el hecho de recibir a estudiantes que han completado su enseñanza media.

Ahora, si consideramos sólo a las Universidades, puede comprobarse que subsiste una enorme heterogeneidad. Es así como, bajo esta denominación, encontramos a instituciones de muy diferentes niveles de complejidad. Desde aquellas que imparten sólo la docencia de pregrado - en algunos casos, en una sola disciplina (Educación); en otros, mayoritariamente en carreras técnicas -, pasando luego a aquellas Universidades que se ocupan también de la investigación, la creación y el desarrollo tecnológico, hasta llegar finalmente a otras, como la nuestra, que además dedican parte importante de sus esfuerzos y recursos al postgrado, al postítulo, la educación permanente y a labores de animación cultural a través de conjuntos estables como la Orquesta Sinfónica, el Teatro Nacional, el Ballet Nacional, y a la preservación del patrimonio cultural de Chile mediante sus bibliotecas y museos.

Pero eso no es todo. También hay diferencias de tamaño, de dimensiones, que van desde Universidades que atienden sólo a algunos cientos de alumnos, hasta otras, como la Universidad de Chile, que enseñan a decenas de miles de estudiantes en distintos niveles educativos.

Por otra parte, las mismas definiciones del carácter de cada Universidad tampoco son homogéneas. Hay algunas que se declaran vinculadas con el desarrollo de la región en que están instaladas, otras que poseen - declaradamente o no una impronta religiosa, filosófica o política, lo que desde luego las orienta en direcciones distintas a las de una corporación como la Universidad de Chile, que se define explícitamente a sí misma como de carácter nacional y pluralista, es decir, comprometida con el desarrollo integral del país, y a donde concurren estudiantes y académicos de todos los credos y de los diversos estratos sociales y culturales que conforman la sociedad chilena.

Si examinamos las estructuras y estatutos jurídicos, encontramos nuevamente grandes disparidades. Algunas, como la Universidad de Chile, dependen del Estado, por lo que están some- 
tidas a sistemas de control y a regímenes de funcionamiento que muchas veces importan severas restricciones y agregan controles engorrosos al trámite administrativo. Otras, de carácter privado, pueden pertenecer a fundaciones, a corporaciones o a distintos niveles de la organización de la Iglesia. Por otra parte, sólo a algunas de estas Universidades privadas, las que pertenecen al Consejo de Rectores, se las considera de servicio público, por lo cual reciben un aporte fiscal que, a veces, es porcentualmente mayor que el que se otorga a las Universidades que pertenecen al Estado de Chile.

Si atendemos, por último, a las formas de financiamiento, encontramos Universidades que se financian íntegramente con los aranceles que pagan sus estudiantes de pregrado; otras que a este ítem agregan los aportes fiscales que hemos mencionado; y otras, finalmente, que añaden, además, fuentes de financiamiento muy diversas, como ventas de servicios académicos y técnicos, donaciones de procedencia nacional e internacional, y aportes que provienen de las utilidades de empresas como canales de televisión o juegos de azar, etc.

Esta desmesurada heterogeneidad tiene, por cierto, consecuencias importantes. En primer lugar resulta extremadamente difícil, si no imposible, aplicar sistemas de evaluación y hacer comparaciones entre las distintas Universidades, sin considerar sus diferencias reales, lo que ciertamente sólo puede hacerse a través de algunos indicadores de gestión muy específicos.

Es indudable que en un conjunto tan heterogéneo no es posible establecer comparaciones globales o de carácter general. Por el contrario, si se quieren realizar contrastaciones válidas, es necesario construir indicadores que den cuenta de la competencia institucional, función por función. Por ejemplo: pregrado, postgrado, postítulo, investigación básica, innovación tecnológica, animación cultural, etc.; o disciplina por disciplina: música, plástica, teatro; carrera por carrera y doctorado por doctorado.

Este, por lo demás, no es un método particularmente novedoso. Se usa desde hace tiempo en la mayor parte de los países desarrollados del mundo.

La distorsión a que me refiero se produce, por ejemplo, cuando se pretende medir, como se ha hecho, la eficiencia de una institución por el simple expediente de dividir el aporte fiscal que ella recibe por el número de estudiantes de pregrado a los que atiende. Como el aporte fiscal legalmente no se orienta a financiar actividades en el pregrado, la correlación que se obtiene carece de sentido, puesto que para algunas Universidades, como la nuestra, este aporte se justifica en función de la investigación que realiza, de las labores de animación cultural que cumple, de los programas de postgrado que desarrolla, es decir, de factores que no se consideran en la operación ya mencionada. De esta manera, prácticamente todas las funciones a las que se destina el aporte fiscal quedan excluidas en aquella correlación con la cual intentan medirnos.

Del mismo modo, se usan indicadores que correlacionan número total de estudiantes de pregrado con jornadas completas equivalentes de académicos, o lo que es peor, con la cantidad total de personal.

Desde luego, las comparaciones que se hagan a partir de las operaciones mencionadas omiten, al menos, en el caso de la Universidad de Chile, la existencia de muchas actividades de investigación o de servicio público en las cuales trabajan especialistas que, en algunos casos, nunca tienen a su cargo a estudiantes de pregrado. Tómese, como ejemplo, el Centro de Estudios Espaciales o la Orquesta Sinfónica y se comprenderá lo que digo. Me parece que la inadecuada consideración de la heterogeneidad de las instituciones de Educación Superior está Ilevando a otro tipo de reducción, que consiste en aplicar como patrón de medida, para todas las Universidades, el modelo más simple, es decir, el de aquellas Universidades que sólo entregan docencia de pregrado y que se financian por el pago directo que hacen los alumnos de esos servicios docentes. Esto, desde luego, afecta a las instituciones de mayor complejidad, como es el caso nuestro. Basta leer algunos artículos de prensa y editoriales que se han publicado, especialmente acerca de la Universidad de Chile, para darse cuenta de la perplejidad y la confusión que algunos medios de comunicación social y ciertos actores sociales y políticos sienten frente a instituciones complejas y multifacéticas, que no pueden evaluarse con el tipo de indicadores que ya he mencionado. El problema está en que dicha perplejidad o confusión no impide que estos medios o estos actores emitan opiniones elaboradas sobre la base de simplificaciones o de fundamentos reduccionistas, 
llegando a conclusiones que a primera vista pueden parecer válidas para los legos, pero que resultan disparatadas para quienes conocen verdaderamente la realidad de nuestra institución o se han detenido a considerar lo que ocurre en el mundo en el ámbito de la Educación Superior, la investigación científica y técnica y el desarrollo cultural.

Este tema no es trivial. Hay quienes, seriamente, postulan que el profundo cambio de civilización que presenciamos o sufrimos está abriendo a la humanidad a lo que se ha llamado la Sociedad del Conocimiento, por entero distinta a la Sociedad Industrial, cuyo tiempo terminó. Los actores políticos y sociales más responsables no pueden seguir, con los simples y toscos conceptos del pasado, pues en este futuro que ahora llega será necesaria más discriminación y análisis particularmente, respecto de quienes producen y difunden conocimientos.

Por otra parte, cuando la heterogeneidad no se aclara ni se asume, puede servir a ciertos propósitos, no siempre diáfanos o cristalinos y por lo mismo difíciles de establecer con precisión. Algunos de estos objetivos son comprensibles, aunque éticamente difíciles de justificar, a partir del juego de competencia por recursos y por audiencias que el actual sistema de financiamiento ha generado. Pero también es necesario reconocer que el asedio a la Universidad de Chile puede tener propósitos de origen ideológico o político que, curiosamente, proceden de posiciones situadas en muy diversas perspectivas. La sola existencia de una institución estatal, que no responde a intereses privados o a fines de lucro, que considera el pluralismo como parte esencial de su vocación, y que además financia el $73 \%$ de sus actividades, resulta problemática para sectores que piensan que el libre mercado, basado en el interés individual, no sólo es el único medio de asignación de recursos, sino el factor que regula todo el funcionamiento de la sociedad. Además, también despierta la desconfianza de otros grupos que aún se aferran a ideologías o sueños que la misma historia se ha encargado de desechar, y que ven cualquiera forma de gestión orientada hacia lograr mayor autofinanciamiento o a establecer modalidades de acción ajustadas a la mecánica del mundo actual, como la amenaza de una privatización indebida. De esta manera, tal vez el único punto de coincidencia de estas posiciones antagónicas está en que preferirían que el pluralismo se derogase, para dejar lugar a alguna de estas ortodoxias de distinto signo. Como se ve, muchos de los asedios que sufrimos cuestionan ya no nuestra calidad en el trabajo académico o nuestra eficiencia institucional, sino que ponen en duda nuestra misión y nuestra historia.

Por otra parte, esta heterogeneidad de propósitos, de naturalezas, de acciones y percepciones, está generando un ambiente al mismo tiempo confuso e inmovilizado, lo que viene a evidenciar la urgencia de que se diseñen políticas públicas que asumiendo realmente nuestras diversidades, den cuenta de la enorme complejidad y riqueza de instituciones tan variadas y legítimas, cada cual en su propio sentido, como son las Universidades chilenas. De aquí que piense que al asumir esta tan evidente heterogeneidad, será posible desarrollar con más propiedad que ahora los mecanismos administrativos y los instrumentos financieros que puedan resolver, según convenga en cada caso, la diversidad de problemas que afectan a instituciones tan distintas. Esto, otra vez, no es tan novedoso en el mundo.

En los Estados Unidos, por ejemplo, las Universidades que realizan investigación, y que no son más del 15\% del total, tienen acceso a un sistema de overhead que significa reconocer y medir los gastos indirectos y de administración que la entidad ha realizado en relación con las tareas de investigación. En el último tiempo, y como parte de la nueva visión económica del Partido Republicano, se ha insinuado que este overhead no puede sobrepasar el $46 \%$ de los recursos obtenidos en concursos de investigación. Este es un sistema simple, impersonal y no arbitrario que financia de manera específica a las Universidades que realizan mayores esfuerzos en la creación del conocimiento. Entre nosotros, en cambio, el overhead de los proyectos FONDECYT $\left({ }^{2}\right)$ es del $10 \%$ y en FONDEF $\left({ }^{3}\right)$ ha sido necesario aportar del presupuesto universitario considerable contraparte para el desarrollo de cada proyecto. Esto significa que en nuestro país no sólo no se premia sino que de algún modo se castiga a las Universidades que más actividad investigativa realizan, lo que desde el punto de vista meramente presupuestario significa que "no conviene" a los intereses institu-

2 Fondo Nacional de Ciencia y Tecnología.

3 Fondo de Fomento. 
cionales hacer investigación. AI mismo tiempo, sin embargo, existen críticas porque los recursos de investigación, especialmente de FONDECYT, se concentran en las grandes Universidades de Santiago. Pero éste es el resultado esperable cuando se usa un instrumento basado sólo en la calidad. Una ayuda adecuada para mejorar la capacidad investigativa de Universidades pequeñas o regionales es diseñar otro mecanismo financiero especial para lograr desarrollo de tal capacidad, lo que por cierto es distinto a concursos que miden sólo calidad técnica de proyectos específicos.

La mayor parte de nuestros pares europeos, es decir, los funcionarios de las Universidades estatales, tienen allí la calidad de empleados públicos, con todas las obligaciones y derechos de esa condición. Por lo tanto, reciben remuneraciones y los aumentos que correspondan, de parte del mismo Estado. Con esto se evita la contradicción manifiesta que se ha producido en Chile, donde los funcionarios de las Universidades del Estado pertenecen a éste para los efectos de Estatuto Administrativo y sus restrictivas regulaciones, pero la Universidad tiene la "libertad" de otorgarles o no los reajustes de sueldos que se dan al resto le los funcionarios públicos. He puesto esta libertad entre comillas porque está supeditada a la disponibilidad de fondos que la misma Universidad pueda generar, porque el Estado provee los recursos para financiar dichos reajustes sólo en relación con el aporte fiscal directo, que en el caso de la Universidad de Chile alcanza más o menos a la mitad de nuestro gasto en personal.

En todas la Universidades del mundo desarrollado y en los países asiáticos, los planes de inversión son financiados, en el caso de las Universidades públicas, por el Estado sobre la base de proyectos específicos que demuestren su calidad, relevancia y pertinencia. En Chile existió algo similar con la Ley 11.575 que entregaba recursos de inversión a las Universidades del Consejo de Rectores, a partir de un impuesto a las utilidades producidas por las ventas de cobre. Como se sabe, esta ley fue abolida en 1977, transformándola en la que actualmente y desde entonces financia inversiones de las Fuerzas Armadas.

He expuesto sólo tres ejemplos, pero hay muchos más, de formas de financiamiento y sistemas de administración que podrían usar diferencialmente las distintas Universidades, de acuerdo con las características propias de cada una, siempre y cuando aceptemos el hecho, por lo demás tan evidente, de la heterogeneidad de nuestro sistema universitario.

Ver texto completo en: www.revistas.uchile.cl 